\section{The Palao Biological Station}

T HE Tropical Biological Station, founded by the Japan Society for the Promotion of Scientific Research, was opened officially in April 1936 with a staff consisting of a director and three researchers drawn from Japanese universities. Its laboratory is situated to the south of Kororu Island in lat. $7^{\circ} 21^{\prime} \mathrm{N}$., about the middle of the main Palao series. The whole group lies 500 miles east of the Philippines and consists of three or four small atolls to the north, a single elevated limestone island to the south and in the centre a great bank about 80 miles long by 15 miles broad with six main islands and more than two hundred islets. Most of the land is situated to the east with fringing reefs, while a great barrier to the west encloses a long narrow lagoon, which reaches a depth of more than thirty fathoms. Andesite and crystalline limestone form the land, the latter in terraces mainly in the southern half. Historically, the group is interesting for Karl Semper ("Animal Life", 1881), on the evidence collected there, was one of the first of that long series of field workers to dissociate himself from Darwin's theory of universal oceanic subsidence to explain the formation of atolls and barrier reefs.

The laboratory is a frame building with sheds and small boats, and provides accommodation for four research workers, who have to devote their attention to biological studies of coral reefs; their expenses are paid by the Society, and each stays at least four months. It is situated on a bay, or secondary lagoon (Iwayama), almost entirely enclosed by high land, which here forms the meeting place of limestone and andesite. The bay is studded with many elevated limestone islets and has depths up to fifteen fathoms ; it lies next to that area where Mikimoto cultures his pearls. Well protected from the trade winds and with small currents, corals grow in great variety, so far 116 species representing 43 genera having been collected. Most are "very delicate and brittle" and "show poor growth" so that the hoped-for comparisons with the vigorous growth of open lagoons and of sea reefs will be difficult. On the other hand, possessing protected environments where corals can be easily planted, the bay should be excellent for the study of the biology and variation of species.

Among the separate reports which follow, Fujio Hiro describes twenty-five cirripedes, leaving their interesting coral commensals to a future paper. $\mathrm{He}$ also studied crabs forming galls on corals, these due to the growth of coral around the young crab which has settled upon it. There is little new here beyond what Potts told us, except to show that the cavities produced vary greatly. A hydrographical study by Matsuya discloses in the bay higher temperature and silica and lower chlorinity, oxygen, $p \mathrm{H}$ and phosphates than in the ocean waters. Noboru Abe undertook the development of Fungia from the planula to the commencement of skeletogenous formation. Fertilization occurs in the gonad at full moon, and the planula there formed is liberated at new moon from September until April. It attaches itself on the third day and the first septa commence to form on the seventh; the growth curve shows a marked and suggestive slowing as soon as the septa commence to form. The development is said to be much delayed by an absence of light; but a deeper study is necessary before many interesting features can be understood.

\section{University Events}

Birmingham,--On October 14 H.R.H. the Duke of Kent, as patron of the Hospitals Contributory Schemes Association, visited Birmingham to attend the annual meeting of the Association. His activities included a visit to the new Hospitals Centre and Medical School, after which at a special degree congregation the Chancellor of the University (Viscount Cecil of Chelwood) conferred on His Royal Highness the degree of LL.D.

With the object of securing closer contact between the University and the two Birmingham municipal hospitals at Dudley Road and Selly Oak, five of the professors of the Medical Faculty of the University have been appointed as part-time consultants to the hospital staffs. The professors are Sir Beckwith Whitehouse, Mr. W. H. Wynn, Mr. Philip Cloake, Mr. William Gemmill and Mr. Seymour Barling. The appointments have been made by the Birmingham Health Committee.

Cambridge.-G. Metcalfe, of Clare College, has been appointed to the Frank Smart University studentship in botany.

G. S. Gough, of Pembroke College, University lecturer in engineering, has been elected into a fellowship at Trinity College on appointment as lecturer in mechanical sciences. C. H. Bamford has been elected into a fellowship at Trinity College for research in natural sciences. He obtained a 1st Class in Part I, Natural Sciences Tripos (1933) and in Part II (1934), (Chemistry). D. M. A. Leggett has been elected into a fellowship at Trinity College for research in applied mathematics. He obtained a lst Class in Part I, Mathematical Tripos (1932), and in Part II (1934), Wrangler (b) distinguished ; Rayleigh Prize, 1936.

The Council of the Senate has reported that the University will eventually benefit under the will of the late Mr. William Charles Wilson, of St. John's College, to the extent of about $£ 15,000$. No conditions are attached. The Council is of the opinion that, in view of Mr. Wilson's interest in the alleviation of human suffering, it would be appropriate to use his bequest for the furtherance of some allied branch of research. It is recommended that the bequest be applied to the provision of an extension of the Psychological Laboratory. Should this recommendation of the Council be approved, the Rockefeller Foundation has promised to give $£ 11,360$, spread over a period of five years from January 1, 1938, towards the cost of developing the Department of Experimental Psychology.

SHEFFIELD.-A contribution of $£ 5,000$, being the second instalment of the contribution of $£ 10,000$ promised by the City Council, has been made to the University Extension Fund.

E. T. Goodwin and T. D. H. Baber have been appointed assistant lecturers in mathematics, and Dr. Helen Mellanby part-time demonstrator for medical and dental students in the Department of Zoology.

The following resignations have been received: Mr. J. W. Frame, of his post of lecturer in mathematics; Mr. J. Jenkins, of his post of lecturer in civil engineering; Dr. E. S. Duthie, of his post of demonstrator in pathology. 